\title{
Storage studies on textural aspects of selected Indian dairy products
}

\author{
Snehal P Lokhande ${ }^{1}$, M Waseem ${ }^{1}$, Rupesh P Datir ${ }^{2}$, Anant V Dhotre ${ }^{1}$ and PG Wasnik ${ }^{1}$
}

Received: 25 November 2019 / Accepted: 14 April 2020 / Published online: 12 July 2020

(c) Indian Dairy Association (India) 2020

\begin{abstract}
The present study was undertaken to study the effect of storage temperature on the textural properties of market samples of Paneer, Kaju Katli and Rajmalai. The investigation was done to know the significance of the effect of ambient (fluctuating) versus steady storage temperature conditions on the textural properties of products. Ambient storage in the glass shelves or jar is the most common and preferred method of storage by sweet vendors in India. So the market samples of products were procured and stored at designated temperature conditions, $\left(5 \pm 1{ }^{\circ} \mathrm{C}, 80 \pm 5 \% \mathrm{RH}\right)$ incubator at $\left(18 \pm 1{ }^{\circ} \mathrm{C}, 55 \pm 5 \% \mathrm{RH}\right)$ and $(30$ $\left.\pm 1{ }^{\circ} \mathrm{C}, 55 \pm 5 \% \mathrm{RH}\right)$, and at ambient condition $\left(18-30^{\circ} \mathrm{C}, 70 \pm 5 \%\right.$ $\mathrm{RH})$ for different time periods. Such products are subjected to fluctuating environmental conditions. The result indicates that, the primary textural characteristics of Paneer and Kaju Katli were not significantly affected by the fluctuation of ambient storage temperature for the short shelf life at that temperature but the adhesiveness, cohesiveness and springiness of Rajmalai were significantly affected by the fluctuation of ambient storage temperature for the long shelf life at that temperature.
\end{abstract}

Keywords: Kaju Katli, Paneer, Rajmalai, Texture-analyser

\section{Introduction}

In India, of the total milk processed, around $65 \%$ to $70 \%$ milk is sold as liquid milk while rest is processed in to various dairy products like cheese, butter, ghee, Paneer, ice-cream, curd etc

${ }^{1}$ Dairy Engineering Section, College of Dairy Technology, Warud (Pusad), MAFSU, Nagpur-440 006, India

${ }^{2}$ Dairy Engineering Section, ICAR-National Dairy Research Institute, SRS, Bangalore-560 030, India

Rupesh P Datir ( $\triangle)$

Dairy Engineering Section, College of Dairy Technology, Warud

(Pusad), MAFSU, Nagpur-440 006, India

Email- rupeshdatir@gmail.com
(ICFA, 2019). Variation in the ingredients, their proportion and processing condition affect the quality of product. Lack of knowledge in these aspects is a serious limitation for the processing standardization and quality control. Instrumental analysis of texture in food provides fast and relatively inexpensive indications on product characteristics and consumer acceptance (Anton and Luciano, 2007).

The literature shows very sparse data on engineering properties of indigenous milk products. Texture is one of the major criteria which consumers used to judge the quality and freshness of many foods. Paneer, essentially had a characteristics harder texture than Chhana. Fresh or fried Paneer had usually been analysed for its textural profile parameters with Instron (Desai, 1988; Zanjad and Mathur, 1990; Rao, 1993). Khan and Pal, (2011) stated that Paneer was highly perishable product. Freshness of Paneer remains intact only for 3 days at refrigeration temperature. At room temperature, Paneer does not stay good for more than a day. Paneer packaged in laminated pouches had a shelf of about 30 days at refrigerated storage. Several compositional and environmental factors have influence on the quality attributes of cashew nut sweets. Moisture reduction below 9.5 per-cent (dry weight basis) renders the product hard in body and coarse in texture, thereby affecting its acceptability (Aneja et al. 2002). Kaju Katli is one of the most popular Indian sweets because of its delicate texture, good flavor and excellent mouthfeel. Major ingredients are milk solids, cashew nut and sugar and it is typically prepared in the form of thin slices cut into diamond shape with silver foil coating. Rajmalai is a khoa based popular sweet in Vidarbha region of Maharashtra state, marketed in the form of chocolate with approximate dimensions 2.5 inch X 1.0 inch X $0.25 \mathrm{inch}$. The base material of Rajmalai is the khoa. Present study will discuss the effect of storage conditions on textural properties of Paneer, Kaju Katli and Rajmalai.

\section{Materials and Methods}

Paneer and Kaju Katli samples were obtained in a lot from the same batch packed and sealed in polythene and cardboard boxes. These boxes were placed in polythene bag to prevent moisture migration during transport. Rajmalai samples were purchased at the same time from the same lot and packed in sealed plastic 
bottles. Samples of all these products were analysed for chemical qualities and textural parameters. Moisture, titratable acidity, ash, and protein content were determined for each product in triplicate by BIS (SP: 18 (Part XI)-1981) while; fat content of Kaju Katli and Rajmalai was determined by BIS (SP: 18 (Part XI)-1981), but fat content of Paneer was determined by (IS:10484, 1983). Total carbohydrate content of all these samples was determined by subtracting the sum of moisture, ash, protein and fat from 100 . Total solid content of all the products was determined by subtracting moisture content from 100. Chemical composition of Paneer, Kaju Katli and Rajmalai are shown in Table1.

\section{Texture profile analysis}

Texture properties of the Paneer, Kaju Katli and Rajmalai samples were determined by TA-XT2i Texture Analyzer (Stable Micro Systems Ltd., UK) equipped with $50 \mathrm{~kg}$ load cell. Cylindrical samples of each product measuring $10 \mathrm{~mm}$ in length and height were subjected to uniaxial compression to 50 per cent of the initial sample height using the Texture Analyzer. At least five replications were performed on each observation.

The deformation curve obtained for a two-bite deformation cycle, using $75 \mathrm{~mm}$ diameter compression plate was used to determine the textural characteristics of samples of the product tempered at $25{ }^{\circ} \mathrm{C}$. Various textural characteristics of the product viz., hardness, fracturability resilience, cohesiveness, springiness, gumminess and adhesiveness were measured from force-time curve (Bourne, 2002). The analyzer settings that were employed to determine the textural attributes of products are presented in Table 2.

\section{Statistical Analysis}

The data obtained from the analysis of all these samples were statistically analyzed to identify the change in textural parameters at different temperature treatments using "One Way ANOVA". Means were compared according to methods described by Snedecor and Cochran (1967).

Treatments given to Paneer, Kaju Katli and Rajmalai samples were as follows:

Control $=$ Ambient temperature storage
$\mathrm{T} 1=$ Storage at steady and controlled temperature of $18 \pm 1{ }^{\circ} \mathrm{C}$ $\mathrm{T} 2=$ Storage at steady and controlled temperature of $30 \pm 1{ }^{\circ} \mathrm{C}$

All statistical analyses were performed using Microsoft Office Excel® 2007 software utilizing the add-on Data Analysis tools to calculate the means, variances, correlations and for performing one-way ANOVA. Results are presented in means \pm standard error of mean (SEM), and statistical significance was set at $\mathrm{p}<$ 0.05. Analysis of variance (ANOVA) was used to determine the main effects of treatments (Gacula and Singh, 1984). Further verification of statistical results was done by making use of Daniel's XL toolbox version 5.08, an MS Excel add-on.

\section{Results and Discussion}

\section{Paneer}

The moisture content of Paneer stored at all temperature conditions showed a decrease with increase in storage period. The product, initially had $54.09 \pm 3.79 \%$ moisture content, lost moisture to the environment as function of storage temperature. The hardness of Paneer stored at refrigeration temperature showed slight variation with increase in storage period, but that stored at ambient and other temperatures showed a definite increase with increase in storage period. The product becomes harder and this is attributed to the corresponding decrease in moisture content, indicated in figure 1 and figure 2. Other primary textural characteristics viz. Adhesiveness, Cohesiveness and Springiness and the secondary textural characteristics viz. Gumminess and Chewiness varied in diverse manner with storage period.

The correlations amongst primary textural characteristics and with moisture content were analyzed. For the refrigeration temperature $\left(5 \pm 1{ }^{\circ} \mathrm{C}\right)$, non-significant correlation between moisture content and hardness, and moderately high inverse correlation between moisture content and adhesiveness (-0.742) were observed. For the controlled storage temperature of $18 \pm 1$ ${ }^{\circ} \mathrm{C}$, strong inverse correlation between moisture content and hardness $(-0.972)$ and between moisture content and adhesiveness $(-0.831)$ is exhibited. For the controlled temperature condition of $30 \pm 1{ }^{\circ} \mathrm{C}$, there is very strong inverse correlation

Table 1 Chemical composition of Paneer, Kaju Katli and Rajmalai

\begin{tabular}{lllc}
\hline Constituent & Paneer & Kaju Katli & Rajmalai \\
\hline Moisture(\%) & $54.09 \pm 0.16$ & $12.05 \pm 0.23$ & $14.85 \pm 0.25$ \\
Fat (\%) & $23.60 \pm 0.12$ & $16.60 \pm 0.12$ & $8.70 \pm 0.31$ \\
Protein (\%) & $17.60 \pm 0.13$ & $10.99 \pm 0.23$ & $6.92 \pm 0.41$ \\
Acidity (\%) & $0.39 \pm 0.04$ & $0.37 \pm 0.02$ & $0.43 \pm 0.03$ \\
Ash (\%) & $1.79 \pm 0.03$ & $1.13 \pm 0.07$ & $1.72 \pm 0.06$ \\
Total carbohydrate (\%) & $2.92 \pm 0.23$ & $59.23 \pm 1.26$ & $67.81 \pm 1.07$ \\
Total solid (\%) & $45.91 \pm 0.65$ & $88.00 \pm 0.75$ & $85.15 \pm 1.28$ \\
\hline
\end{tabular}


Fig. 1 Variation in the moisture content of Paneer with storage period at different storage temperature conditions

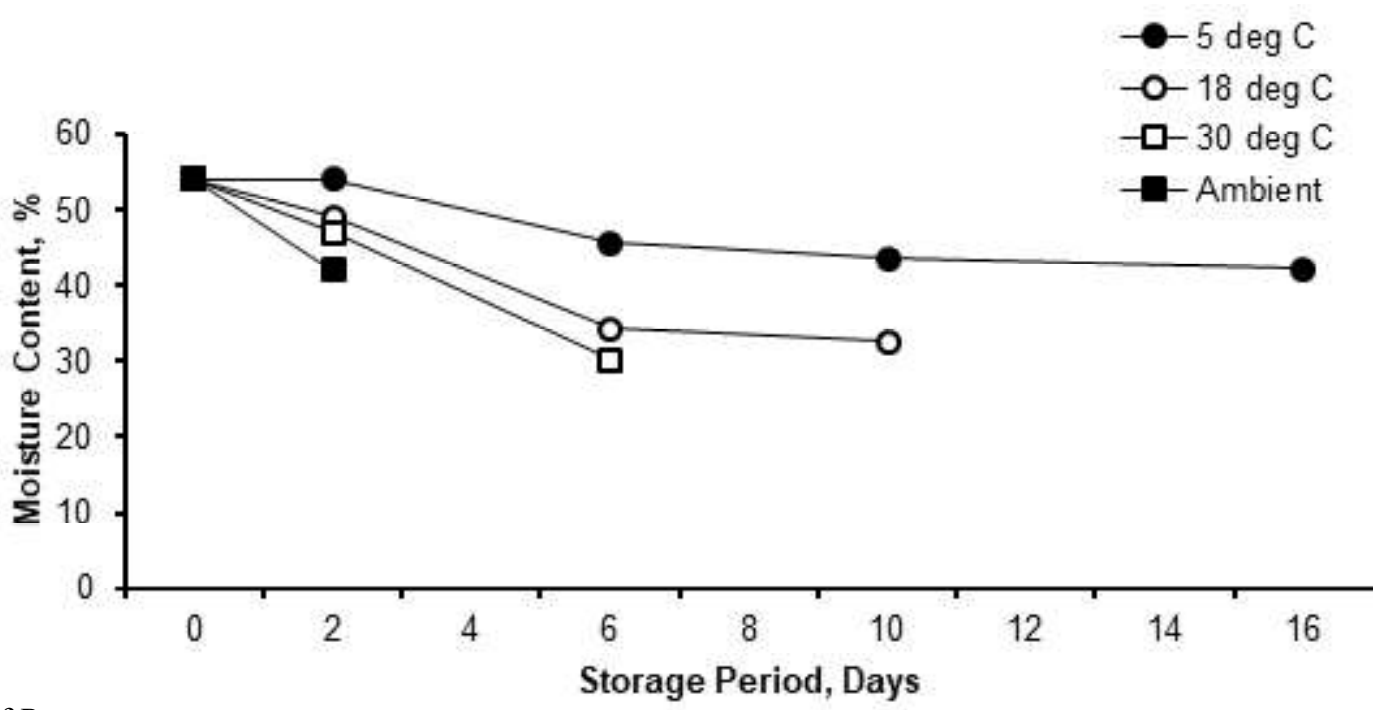

Fig. 2 Variation in the hardness of Paneer with storage period at different storage temperature conditions

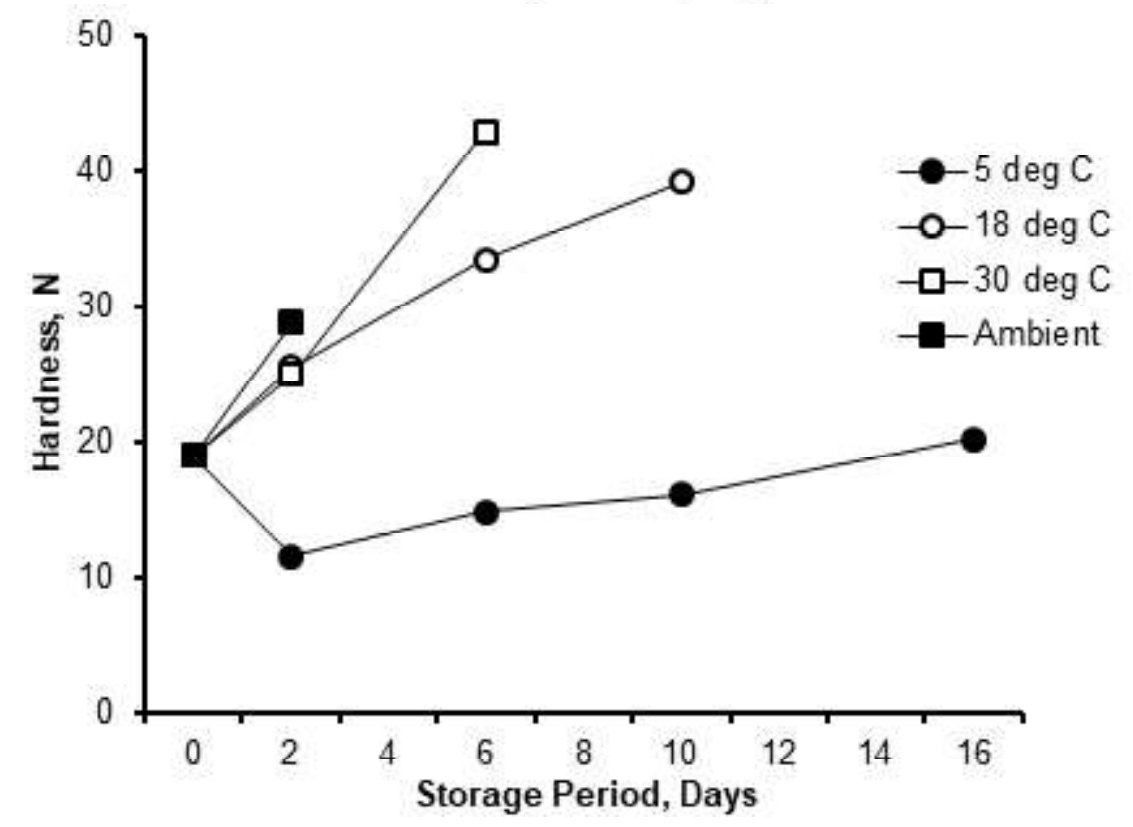

Table 2 Texture analyzer TA-XT2i settings for the present study

\begin{tabular}{lc}
\hline Texture analyzer parameters & Values \\
\hline Pre-test speed & $2 \mathrm{~mm} / \mathrm{sec}$ \\
Test and Post-test speed & $0.5 \mathrm{~mm} / \mathrm{sec}$ \\
Trigger type & Auto \\
Threshold & $0.049 \mathrm{~N}$ \\
Time & $5 \mathrm{~s}$ \\
Distance & $5 \mathrm{~mm}$ \\
Data acquisition rate & $200 \mathrm{pps}$ \\
\hline
\end{tabular}

between moisture content and hardness (-0.999). Adhesiveness exhibited strong inverse correlation with moisture content ($0.964)$. Cohesiveness is strongly correlated with moisture content (0.936). For the fluctuating ambient temperature condition (18 $30^{\circ} \mathrm{C}$ ), very strong inverse correlation between moisture content and hardness $(-0.996)$ and between moisture content and adhesiveness $(-0.997)$ is observed. Cohesiveness is highly correlated with moisture content $(0.946)$. Springiness exhibited non-significant relationship with other textural parameters at all temperature conditions. It is concluded that the variation profile of the moisture content over a period of time is one of the important determining factors for the consumer acceptance of Paneer based upon its texture.

The TPA values of Paneer primary textural characteristics under the fluctuating ambient temperature conditions $\left(18 \sim 30{ }^{\circ} \mathrm{C}\right)$ and the two comparable controlled temperature conditions during the short shelf-life period were subjected to Two-factor Analysis of Variance at 5 per cent level of significance. It was observed that values of hardness changed significantly over the short storage period (P: $0.02576<0.05)$ as expected for high-moisture food, but there is statistically insignificant variation amongst the 
Fig. 3 Variation in the moisture content of Kaju Katli with storage period at various temperature conditions

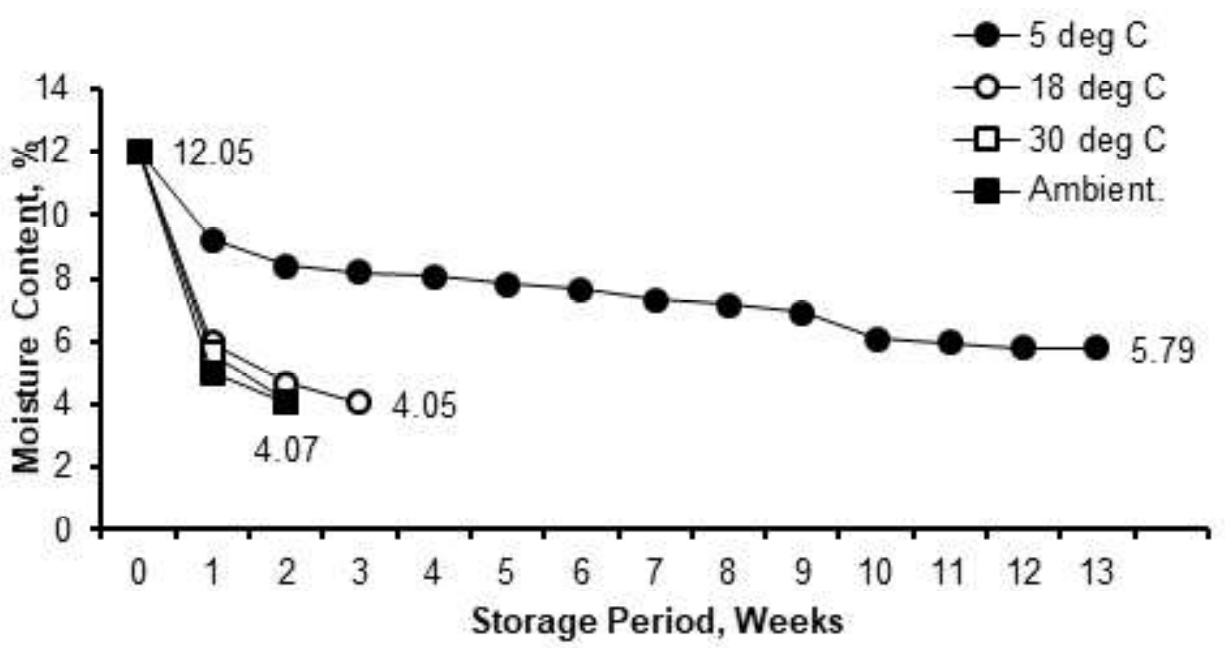

Fig. 4 Variation in the hardness and moisture content of Kaju Katli with storage period at refrigeration temperature condition

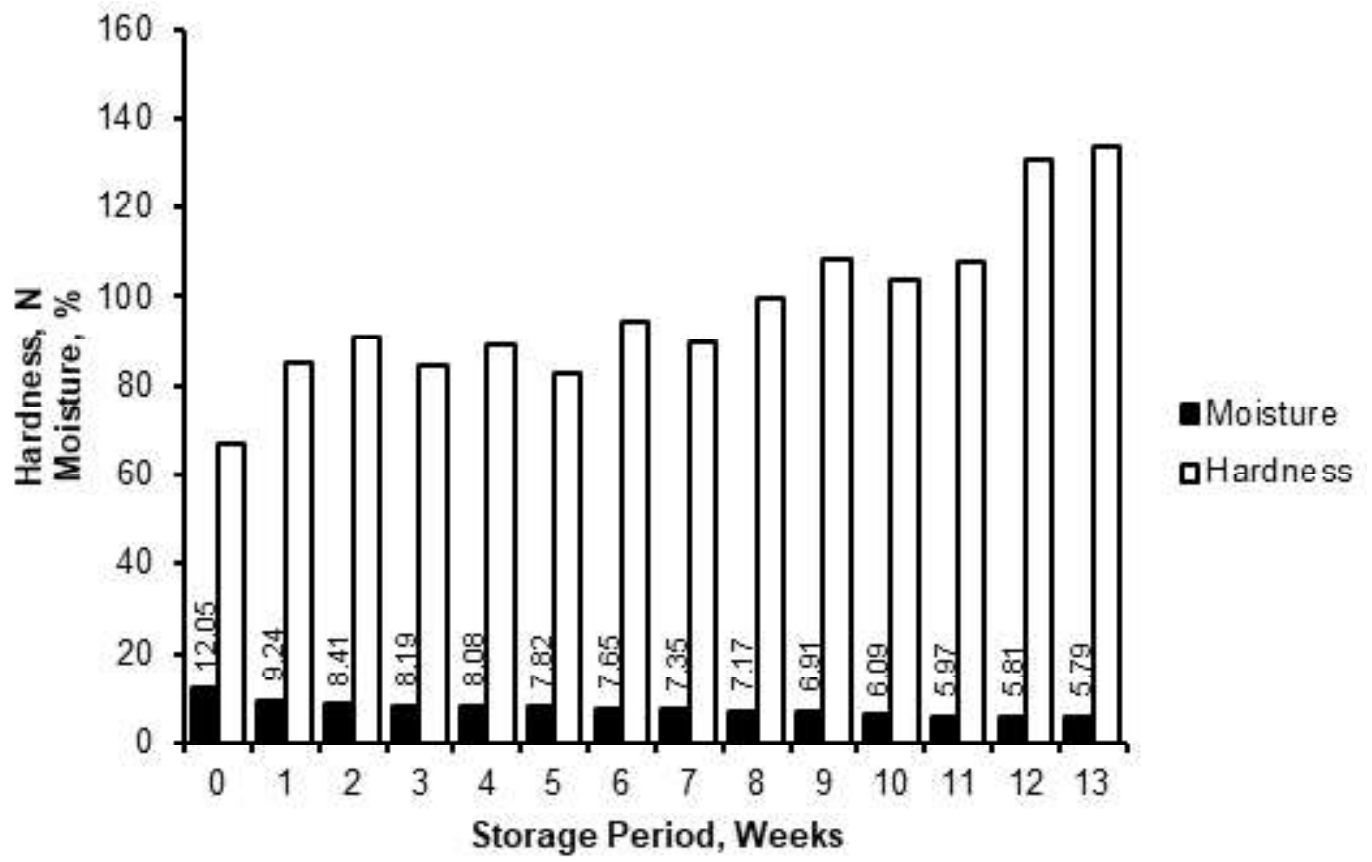

storage temperature conditions $(\mathrm{P}: 0.5>0.05)$. This implies that the hardness of Paneer is not significantly affected by the fluctuation of ambient storage temperature, for the short shelf life at that temperature. The other primary textural characteristics of Paneer are also not significantly affected by the fluctuation of ambient storage temperature, for the short shelf life of about 2 days at that temperature. Bargale and Jha (1992) concluded that as the storage period increased, hardness, chewiness, and gumminess increased significantly, while springiness and cohesiveness remained almost unchanged.

\section{Kaju Katli}

The correlations amongst primary textural characteristics and with moisture content were analyzed (indicated in figure 3 and figure 4$)$. For the refrigeration temperature $\left(5 \pm 1{ }^{\circ} \mathrm{C}\right)$, $)$, high inverse correlation of moisture content with hardness $(-0.849)$ and moderately high inverse correlation with adhesiveness (0.763 ) was observed. Cohesiveness is moderately correlated with moisture content (0.712). For the controlled storage temperature of $18 \pm 1{ }^{0} \mathrm{C}$, strong correlation of moisture content with cohesiveness (-0.910) and with springiness (0.943) was exhibited. For the controlled temperature condition of $30 \pm 1{ }^{\circ} \mathrm{C}$, moderately high inverse correlation of moisture content with hardness (0.749 ) and moderate correlation with cohesiveness $(0.751)$ were observed. Springiness exhibited strongly significant relationship with the moisture content $(0.978)$. For the fluctuating ambient temperature condition $\left(18 \sim 30^{\circ} \mathrm{C}\right)$, very strong inverse correlation of moisture content with hardness $(-0.966)$, strong correlation with springiness $(0.960)$, and moderately inversely with adhesiveness (-0.736) and cohesiveness (-0.735) was observed. The hardness of Kaju Katli was found to be inversely correlated 
Fig. 5 Variation in the moisture content of Rajmalai with storage period at different storage temperature conditions

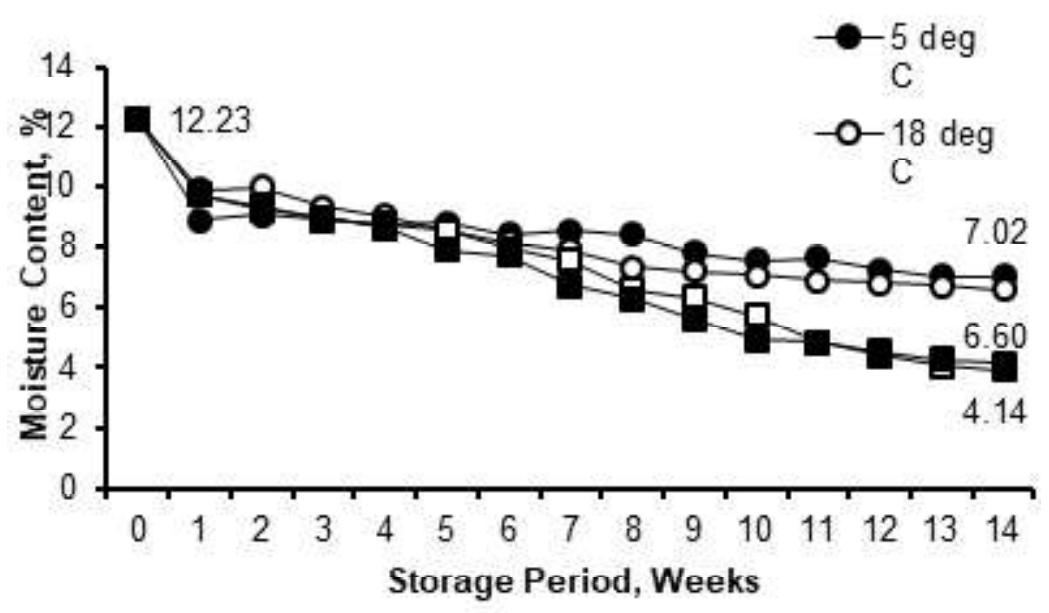

Fig. 6 Variation in the hardness of Rajmalai with storage period at different storage temperature conditions

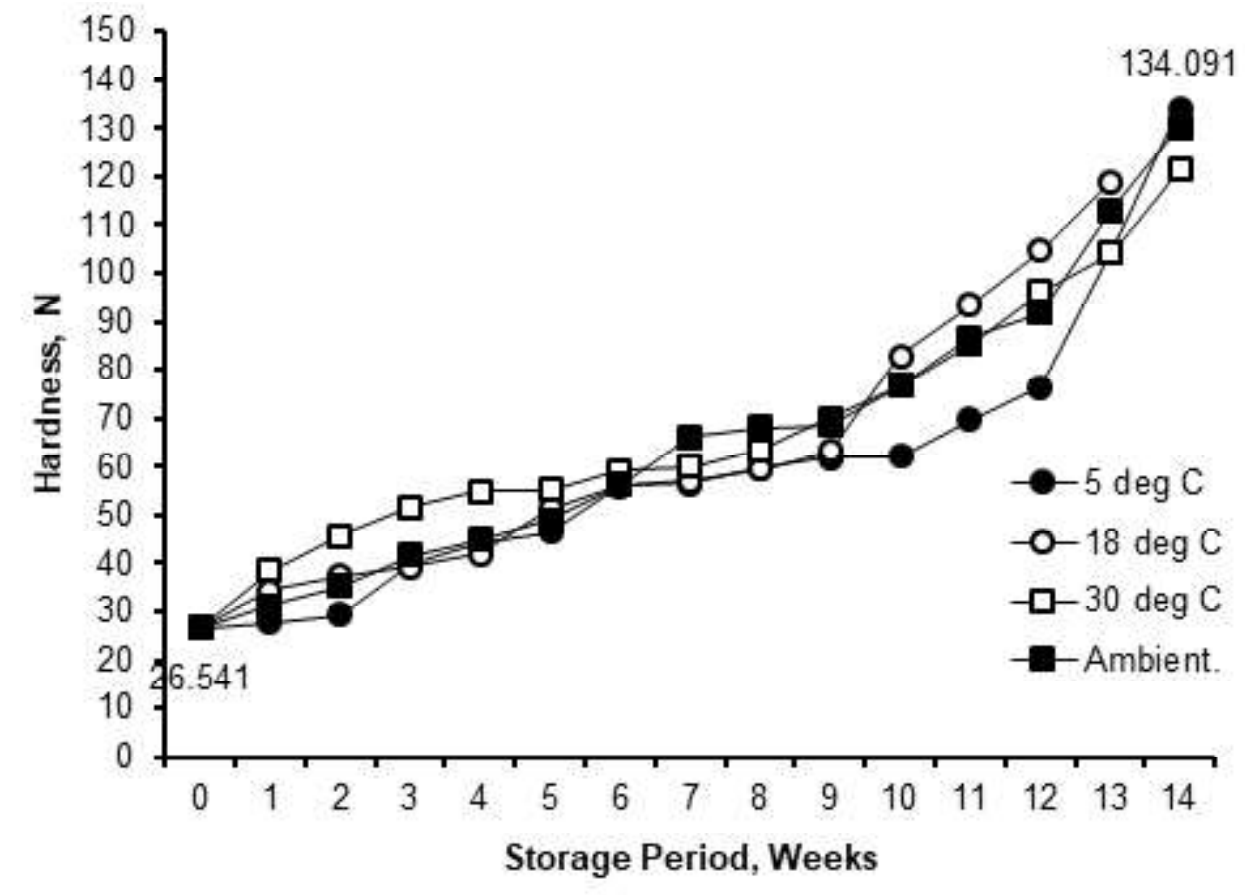

with the moisture content in moderate to highly strong manner, while other primary textural parameters were also observed to be correlated with the moisture content with varying intensity. Sharma et al. (2017) observed that the hardness of Kaju Katli was found to be increased with decrease in free moisture content over a longer storage period. Hence it is concluded that the variation in moisture content over a period of time significantly affects the consumer acceptance of Kaju Katli based on its texture.

The TPA values of Kaju Katli primary textural characteristics under the fluctuating ambient temperature conditions $(18 \sim 30$ ${ }^{0} \mathrm{C}$ ) and the two comparable controlled temperature conditions during the shelf-life period were subjected to Two-factor Analysis of Variance at $5 \%$ level of significance. It is observed that the values of hardness changed insignificantly for the short storage period (P: $0.1096>0.05)$ as well as there is statistically insignificant variation amongst the storage temperature conditions $(\mathrm{P}: 0.1506$ $>0.05)$, implying that the hardness of Kaju Katli is not significantly affected by the fluctuation of ambient storage temperature, for the short shelf life at that temperature. Also, there are insignificant changes in primary textural characteristics on account of temperature fluctuations under ambient conditions. The common market practice of storage of Kaju Katli under ambient temperature conditions does not adversely affect its textural quality for the indicated shelf life.

\section{Rajmalai}

The correlations amongst primary textural characteristics and with moisture content were analyzed (indicated in figure 5 and figure 6$)$. For the refrigeration temperature $\left(5 \pm 1{ }^{\circ} \mathrm{C}\right)$, it is seen that there is moderate inverse correlation of moisture content 
with hardness $(-0.732)$ and moderately high correlation with adhesiveness $(0.849)$. For the controlled storage temperature of $18 \pm 1^{\circ} \mathrm{C}$, high inverse correlation of moisture content with hardness $(-0.835)$ and moderate inverse correlation with springiness $(-0.759)$ and adhesiveness $(-0.771)$ is exhibited. For the controlled temperature condition of $30 \pm 1{ }^{\circ} \mathrm{C}$, there is very strong inverse correlation of moisture content with hardness ($0.955)$ and strong correlation with adhesiveness $(-0.888)$. For the fluctuating ambient temperature condition $\left(18 \sim 30^{\circ} \mathrm{C}\right)$, very strong inverse correlation of moisture content with hardness (-0.911) and with adhesiveness (-0.909) is exhibited. The hardness of Rajmalai was found to be inversely correlated with the moisture content in a strong manner, while adhesiveness was also observed to be highly inversely correlated with the moisture content. However, cohesiveness and springiness did not exhibit any significant relationship with the moisture content. It is concluded that the variation profile of the moisture content over a period of time is important for the consumer acceptance of Rajmalai based upon texture.

The TPA values of Rajmalai primary textural characteristics under the fluctuating ambient temperature conditions $\left(18 \sim 30^{\circ} \mathrm{C}\right)$ and the two comparable controlled temperature conditions during the shelf-life period were subjected to Two-factor Analysis of Variance at $5 \%$ level of significance. It is observed that the values of hardness changed significantly for the long storage period $(\mathrm{P}: 2.71 \times 10-17<0.05)$ but there is statistically insignificant variation amongst the storage temperature conditions (P: $0.47696>0.05$ ), implying that the hardness of Rajmalai is not significantly affected by the fluctuation of ambient storage temperature, for the studied shelf life at that temperature; but there are statistically significant changes at $5 \%$ level of significance in other primary textural characteristics viz. adhesiveness (P: $0.000108<0.05$ ), cohesiveness (P: $0.018688<0.05)$ and springiness $(\mathrm{P}: 0.018562<$ $0.05)$ on account of temperature fluctuations under ambient conditions were. Nightingale et al. (2011) reported the textural changes in dark chocolate stored at ambient (storage room) and temperature fluctuations. The percent change in hardness, cohesiveness and springiness after 8 weeks of storage was less than 10 per cent for temperature fluctuations environment. Chand et al. (2011) prepared and packed jaggery chocolate and then subjected them to different storage conditions, including ambient $\left(25-35^{\circ} \mathrm{C}\right)$ and reported increased in hardness with increased in storage period.

The common market practice of storage of Rajmalai under ambient temperature conditions does adversely affects its textural quality for the indicated long shelf life, and textural variations over the storage period can be minimized by storing the product in steady temperature environment.

\section{Conclusions}

Moisture content of a product has direct bearing on its textural characteristics. The variation profile of the moisture content over the storage period is an important factor for determining consumer acceptance of the product based upon texture. The common market practice of storage of Indian dairy products under ambient temperature conditions affects the textural quality for long shelf life products but for short shelf life products, the textural variations over the storage period are insignificant.

\section{Acknowledgements}

The authors are thankful to the Associate Dean, College of Dairy Technology, Warud, Pusad for providing all necessary facilities and fund for conducting the presented research work.

\section{References}

Aneja RP, Mathur BN, Chandan RC, Banerjee AK (2002) Technology of Indian Milk Products, 1 st Ed. A Dairy India Publication, Delhi, pp. 113-120.

Anton AA, Luciano FB (2007) Instrumental texture evaluation of extruded snack foods: A Review, Cienc Technol Aliment 5: 245-251

Bargale PC, Jha K (1992) Changes in the instrumental texture profile of pasteurized tofu (soy Paneer) during storage. Indian J Dairy Sci 45: 429-431

BIS (1981) Hand Book of Food Analysis. Part XI, Dairy Products, Indian Standard Institution, New Delhi.

BIS IS 10484:1983 (R2005) Specification for Paneer, New Delhi.

Bourne M (2002) Food Texture and Viscosity, Academic Press. San Diego, United States of America.

Chand KA, Singh, Verma KA (2011). Quality evaluation of Jaggery chocolate under various

storage conditions. Sugar Tech 13: 150-155

Desai HK (1988) Rheological properties of heat and acid coagulated Indian milk products. Unpublished Ph.D. Thesis Kurukshetra University, Kurukshetra (India), 156-178

Gacula, MC, Singh J (1984) Statistical methods in food and consumer research, Orlando, Florida Academic Press, Inc. pp. 85-86

ICFA (2019) Indian Dairy Product Market (Accessed from http://icfa.org.in/ assets /doc/reports/Indian_Dairy_Product_Market.pdf dated 20/10/ 2019).

Khan SU, Pal MA (2011) Paneer production: A Review. J Food Sci Technol 48: $645-660$

Nightingale LM, Lee SY, Engeseth NJ (2011) Impact of storage on dark chocolate: Texture and Polymorphic changes. J Food Sci 76: 143152

Rao JK (1993) Application of Hurdle Technology in the Development of Long Life Paneer based Convenience Food, Ph. D. thesis, N.D.R.I., Karnal

Sharma AK, Brahmbhatt JV, Patel AM (2017) Storage study of standardized Kajukatli. IJSART, 3: 406-409

Singh PK, Jha A (2005) National workshop on Entrepreneurship development in dairy and food industry on "Economics of traditional milk products manufacturing: A guide for entrepreneurs", December, 23, NDRI, Karnal, India, pp.68-71

Snedecor, GW, Cochran WG (1989) Statistical methods (8th Ed) Ames, Iowa, Blackwell Publishing Professional

Zanjad, PN, Mathur BN (1990) Storage behaviour of inpacked sterilized Paneer: Sensory quality and texture profile analysis. XXIII Intern. Dairy Congr., Ontario, Brief Communication 